Male and female patients progressed equally well. Those under 30 years of age and those whose asthma had lasted 20 years or less fared the best. The severity of asthma and the type of trigger also provided differences in response to hypnosis; mild cases and those with emotional triggers did best, but good responses were observed in the other categories. Patients who were easily hypnotized, those who achieved deep trances, and, perhaps most important, those who could practise the daily use of autohypnosis did best.

Despite the many questions yet to be answered, hypnosis is of value in the symptomatic treatment of asthma as assessed by the reduction in wheezing and in the use of drugs.

We are indebted to Dr. R. S. Bruce Pearson for allowing patients under his care to be studied in this trial by two of us (Lionel Fry and A. A. Mason). We would like to acknowledge, with thanks, the most valued help given by two members of the Statistical Research Unit of the Medical Research Council: Dr. Ian Sutherland, who helped greatly in planning the trial, and Miss B. J. Kinsley, who converted the data on the charts into comprehensible tables and who gave most valuable help and advice in preparing the paper. Our thanks are due to Mrs. M. Curry (Colindale Hospital) and to Mr. J. Maher-Loughnan for painstakingly crosschecking the data.

\section{REFERENCES}

Ambrose, G. J., and Newbold, G. (1958). A Handbook of Medical Hypnosis, 2nd ed. Baillière, Tindall and Cox London.

Edwards, G. (1960). Brit. med. J., 2, 492.

Francis, R. S., and Spicer, C. C." (1960). Ibid., 1, 297

Fry. A. (1957). Brit. med. J., 1, 1323.

Magonct, A. P. (1955). Hypnosis in Asthma. Heinemann, London.

Meares, A (1960). A System of Medical Hypnosis. Saunders. Smith, J. M. (1958). Lancet, 2, 1248.

- and Burns, C. L. C. (1960). Brit. J. Dis. Chest, 54, 78

Stewart, H. (1957). Brit. med. J., 1, 1320.

Waller, R. E., and Lawther, P. J. (1957). Ibid., 2, 1473.

\title{
INFECTIOUS HEPATITIS IN A VILLAGE COMMUNITY
}

\section{KATHLEEN T. FLANAGAN, M.B., B.S. D.Obst.R.C.O.G. \\ General Practitioner, Bourne End, Bucks}

The epidemiology of infectious hepatitis is still not fully understood. In this country sporadic cases are more common than epidemics, and case-to-case infection has been regarded as uncommon and multiple cases within a household as relatively rare. Furthermore, because the responsible virus has only recently been isolated by Rightsel et al. (1961) the diagnosis must be made on clinical grounds. Thus a febrile illness characterized by a prodromal phase with anorexia and nausea and followed by jaundice with liver-function tests indicating evidence of hepato-cellular damage and some degree of biliary obstruction is usually diagnosed as infectious hepatitis. The majority of cases run a benign course with clinical recovery taking place in about four to six weeks. An occasional case may progress to acute hepatic necrosis. The present epidemic is reported because of the large numbers of cases occurring within a closed community with a high incidence in children, multiple cases within families, and one fatality occurring in a young married woman.

The first case was diagnosed in January, 1960, and occurred in a child aged 5 attending a village primary school. During the next seven months a large number of cases of jaundice occurred in the village, and details of 61 have been included in this report, the number occurring in each month being shown in Table $I$ and the age distribution in Table II.

From these Tables it may be seen that the maximum age incidence fell in the primary school age-group and

Table I.-Number of Cases Occurring in Each Month

\begin{tabular}{|c|c|c|c|c|c|c|c|c|c|c|}
\hline No. of cases & $\underset{1}{\operatorname{Jan}}$ & Feb. & $\underset{6}{\operatorname{Mar}}$ & Apr & May $_{12}$ & $\begin{array}{c}\text { June } \\
16\end{array}$ & $\underset{6}{\text { July }}$ & $\underset{6}{\mathrm{Aug}}$ & Sept & Oct \\
\hline
\end{tabular}

Table II.-Age Distribution of 61 Patients

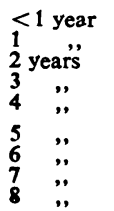

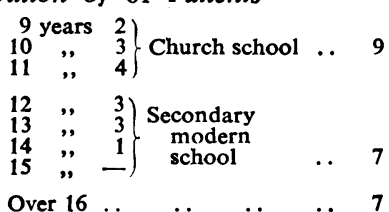

BY

\author{
JOHN LISTER, M.D., F.R.C.P. \\ Consultant Physician, Windsor Group of \\ Hospitals
}

that the incidence of new cases rose steadily to a maximum of 16 in June and thereafter fell steeply with no new cases after August.

\section{Clinical Features}

The 61 cases reported occurred within 35 families. In 20 families there was only one case, in seven there were two cases, in seven three cases, and in one family six cases. In most families the first case to occur was in a child attending the primary school. The incubation period for further cases appeared to be up to the expected 28 days, but as the epidemic developed there were often several separate sources of contact possible, making an exact determination of the incubation period impossible.

The clinical features followed the classical description of the disease. Prodromal symptoms appeared two to five days before jaundice developed, but extended over 10 days in one case. Nausea, anorexia, lassitude, and abdominal pain, with fever varying from 99 to $101^{\circ} \mathrm{F}$. $\left(37.2\right.$ to $\left.38.3^{\circ} \mathrm{C}.\right)$, were constant features. Vomiting was severe and persisted for two to three days in $20 \%$ of the cases, and in these epigastric pain was usually severe. Diarrhoea was present in a few cases. Jaundice with dark urine and pale stools was apparent by the fourth day in most cases. The liver was enlarged and tender for one to two weeks in mild cases but for longer periods in the more severe attacks. In six cases the jaundice persisted for four to five weeks, but in the remaining juvenile cases recovery was rapid and complete and no recurrence was reported. Epistaxis occurred in six cases and melaena was reported in the case of a child who had severe abdominal pain and diarrhoea during the second week of the illness. Pruritus was a troublesome symptom in several cases and lasted for two weeks after the disappearance of jaundice in one case. The adult patients were all more seriously ill, and a married woman of $\mathbf{3 1}$ developed acute hepatic necrosis and died in hepatic coma.

Where possible the children were isolated from other members of the family and all were excluded from 
school for a minimum of three weeks from the onset of the symptoms. In houses where overcrowding prevailed isolation was impossible, but the incidence of the disease was no higher there than in those in which cases were isolated. Indeed, the reverse was noted, and in one family living in appalling conditions several children escaped infection whereas in another family living in excellent conditions all the children became jaundiced.

It seems certain that in addition to the cases of frank jaundice there were a large number of cases of subclinical infection, and the spread of the disease was clearly facilitated by these cases and by children remaining at school with prodromal symptoms.

Pathological Investigations.-Apart from the fatal case only one case was admitted to hospital, and therefore pathological investigations were carried out in only seven cases. A leucopenia with atypical lymphocytes was usually present; the serum bilirubin ranged from 1.2 to $7 \mathrm{mg}$. $/ 100 \mathrm{ml}$., the thymol turbidity ranged from 6 to 9 units $/ 100 \mathrm{ml}$., and the alkaline phosphatase from 10 to $48 \mathrm{~K}$.-A. units. In five cases in which the serum glutamic pyruvic transaminase was estimated the figure ranged from 29 to 1,070 units.

\section{Source of the Epidemic}

In nearly every case some contact, direct or indirect, could be traced with the primary school. In view of this, the help of the medical officer of health was sought. He reported that although the infants share the same building with the secondary modern school there is no contact between teachers or pupils and they have separate playgrounds, ablutions, and toilets. They share the same canteen but have separate sittings.

The school comprises 117 pupils (ages 5-7 years) with form classes of approximately 30 pupils in approximately equal sex ratio.

Sanitation includes an open trough urinal for the boys, situated 40 yards ( 36.5 metres) from the nearest school building, and a series of chemical closets, two for the boys and four for the girls. The levers operating the "chemical flush" of the closets are difficult to manipulate so that the very young may be unable to use them satisfactorily.

Ablutions are situated in the main school building with adequate hot and cold running water, and all the children staying to lunch bring their own towels.

It was interesting to note that, although the local practitioners were able to identify 31 of the cases as attending the primary school, the authorities had a record of only 15 cases in the school. The M.O.H. did report, however, that during the Easter term, 1960, between 25 and 30 pupils were away for two or three periods of separate absence, each of about two or three days. All complained of sickness and diarrhoea. Furthermore, it was reported that one of the adult cases was a worker in the primary school canteen, while the headmistress herself was suspected of having subicteric hepatitis. Of the 15 cases known by the school to have developed jaundice, 12 had school lunches. No relationship with any specific inoculation programme could be established. Of the 15 cases reported by the school, nine were in females and six in males.

\section{Discussion}

Although in normal peacetime conditions in this country sporadic cases of infectious hepatitis are commoner than epidemics, it is well recognized that epidemics may occur, especially in closed communities such as schools. Indeed, Glover and Wilson (1931) described an extensive school epidemic, and Pickles (1939) stressed the frequency with which epidemics of infectious hepatitis could be traced to schools. Tilley (1960) described such an epidemic involving 27 children. This epidemic was characterized by a high attack rate for females and minimal spread to family contacts outside the school. There was no increased incidence among children lunching at school, no food-handlers were affected, and no relation to any vaccination programme was established. Toilet facilities were, however, inadequate, and were thought to be the likely means of the bowel-mouth transmission of the disease. The importance of this mode of transmission was also further stressed by the observations of Ward et al. (1958) in their study of 350 cases of infectious hepatitis occurring in an institution for mentally defective patients over a five-year period. They produced evidence that hepatitis virus may be present in stools excreted during the incubation period of two to three weeks before the onset of jaundice, a finding which clearly has a considerable bearing on the infectious period of the disease.

Apart from bowel-mouth transmission occurring as the result of faulty toilet hygiene, the possibility of certain epidemics being due to water-borne infections has been considered. Mosley and Smither (1957) point out that this is rare but believe that it may be more frequent than is reported, particularly in rural areas where water supplies are often poorly protected.

In the present epidemic one food-handler at least was infected, the toilet facilities were not regarded as ideal, and a large number of children affected lunched at the primary school. On the other hand, there was a high incidence of spread to family contacts of the children originally affected in the primary school.

It would seem likely that direct contact was therefore a factor, although several practitioners observed that the incidence of multiple cases within families was not necessarily high in the most overcrowded houses. At the time of the epidemic the village was not on main drainage, so that the possibility of a water-borne factor should perhaps also be considered. especially as sporadic cases have been occurring frequently in the district for several years. On the other hand, as the disease is not notifiable it is not possible to know the number of cases reported annually nor how this might compare with standard rates for the country.

In the juvenile cases in the epidemic the outcome has apparently been universally favourable, but one fatal case occurred in a young mother of one of the children. Such an outcome is usually regarded as rare, reported mortality rates for large outbreaks being of the orde. of 2 per 1,000 cases (W.H.O., 1953). Nevertheless, it should be recognized that the disease does carry a mortality, and any effort to understand the mode of spread would seem justified. Notification has been considered too difficult to be likely to give reliable statistics-but adequate epidemiological and virological information still seems lacking. Certainly, in the epidemic reported here, much more information could have been obtained had the disease been notifiable. Indeed, the extent of the epidemic was doubtless far greater than the 61 reported cases would indicate, since several practitioners were unable to trace all the cases they had treated when they were asked in retrospect to do so. 
Furthermore, had the extent of the epidemic been more fully appreciated it might have been possible to co-ordinate the work of the various practitioners in the district and to have advised upon the use of such protective measures as gamma-globulin.

\section{Summary}

Details of an epidemic of infectious hepatitis occurring in a village community are reported.

The source of infection appeared to be the village primary school, where at least one food-handler was affected and toilet facilities were not regarded as ideal.

The epidemic was subsequently characterized by a high incidence of spread to family contacts of the children originally affected.

Although the clinical course was mild in children, a young married woman developed acute hepatic necrosis and died.

It is believed that the extent of the epidemic was far greater than the 61 cases reported would indicate, and it is suggested that some form of notification of infectious hepatitis is desirable in order to improve our knowledge of the aetiology and epidemiology of this disease.

We wish to record our thanks to Drs. P. C. Green, R. H. Kipping, W. J. Low, and H. N. Smith, who supplied details of cases occurring in their practices, and Dr. A. J. Muir, Medical Officer of Health for the area, for his report. We also thank Professor Sheila Sherlock for her helpful comment.

\section{REFERENCES}

Glover, J. A. A., and Wilson, J. (1931). Lancet, 1, 722 Mosley, J. W., and Smither, W. W. (1957). New Engl. J. Med., 257, 590 .

Pickles, W. N. (1939). Eptdemiology in Country Practice, p. 59. Wright, Bristol

Rightsel, W. A., Keltsch, R. A., Taylor, A. R., Boggs, J. D., and McLean, I. W. (1961). J. Amer. med. Ass., 177, 671.

Tilley, J. D. McD. (1960). Brit. med. J., 2. 1354.

Ward, R., Krugman. S., Giles, J. P., Jacobs, A. M., and Bodansky, O. (1958), New Engl, J.Med. 258, 407.

World Health Organization (1953). Tech. Rep. Ser., No. 62.

According to the Report on War Pensioners for 1961 the Ministry of Pensions and National Insurance was paying 700,000 war pensions-about 268,000 for the 1914 war and 431,500 for the 1939 war-at the end of 1961 . The total includes about 506.000 disablement pensions, about 138,000 widows' pensions, and 56,000 pensions for parents, orphans, and other dependants. The amount being paid in war pensions and allowances at the end of 1961 was at the rate of more than $1100 \mathrm{~m}$. a year. The report is made jointly by the Ministry of Pensions and National Insurance, the Minister of Health, and the Secretary of State for Scotland, and includes an account of medical and surgical treatment for the war disabled and details of welfare work, and other war pensions activities in the various regions. Limbs and appliances supplied and repaired by the Ministry of Health included 3,237 artificial legs and arms supplied and 31,779 repaired ; 6,953 appliances of various kinds, 776 artificial eyes, and 11,107 surgical boots were also supplied. The number of invalid chairs and tricycles in use at the end of 1961 was 4,632 ; the number supplied during the year was 955 . The number of motor-cars in use at the end of 1961 was 3,122 and 1,490 were issued during the year. A new artificial limb and appliance centre was opened at Liverpool in July, 1961. The new Birmingham centre was formally opened in January this year and good progress is being made with the new Portsmouth centre. (H.M.S.O., price $6 \mathrm{~s} .6 \mathrm{~d}$.)

\section{Preliminary Communications}

\section{Mosaicism in a Mother with a Mongol Child}

The simple trisomic condition commonly associated with mongolism can be referred to the failure of homologous chromosomes, or of sister chromatids, to go to opposite poles during gametogenesis. Non-disjunction leading to trisomy 21 (Denver system) usually occurs in individuals with normal chromosome complements (primary non-disjunction) and is influenced by aetiological factors associated with maternal age.

The bimodality of the maternal age effect observed in mongolism (Penrose, 1951, 1954, 1961) suggests that in a proportion of cases factors independent of maternal age are of importance. Penrose further points out that investigation of familial examples of mongolism again shows the presence of a group in which maternal age is not an appreciable aetiological factor.

Chromosome abnormalities, translocations, and/or isochromosomes, not referable to primary non-disjunction, have been described in mongols born to young mothers (Polani et al., 1960 ; Penrose, 1961). This type of abnormality may account for a substantial part of that proportion of cases where aetiological factors other than maternal age are of importance. Translocations and/or isochromosomes have also been shown to be a cause of familial mongolism (Penrose et al., 1960 ; Carter et al., 1960 ; Hamerton et al., 1961).

Another variant of the simple trisomic condition is 21-trisomy/normal mosaicism (Clarke et al., 1961; Fitzgerald and Lycette, 1961 ; Nichols et al., 1961; Hayashi et al., 1962 ; Richards and Stewart, 1962). In 21 -trisomy/normal mosaicism some tissues (or parts of tissues) of a single individual are composed of cells with an extra chromosome No. 21 and other tissues of cells with a normal chromosome complement. It is reasonable to suppose that some mosaic individuals will have only slight signs of mongolism or be clinically indistinguishable from members of the general population. The patients described by Clarke et al., Fitzgerald and Lycette, and Hayashi et al. exhibit the physical features of mongolism in a very incomplete form. If the gonads are involved in this mosaicism (gonadal mosaicism) some offspring would be expected to inherit an extra chromosome No. 21 (secondary non-disjunction) and to exhibit mongolism. Mosaicism leading to secondary non-disjunction is then a potential cause of familial mongolism (Penrose, 1959 ; Clarke et al., 1961 ; Hamerton et al., 1961) and of mongolism which is independent of maternal age. This communication deals with a young married woman who shows some of the features of mongolism and has a mosaic karyotype. Her daughter is a classical case of mongolism and has the standard trisomic condition.

\section{Main Clinical Features}

The propositus (Fig. 1), a 31-year-old married woman, came to the attention of one of us (E. G.) because of anxiety symptoms with hysterical features. Mental subnormality (I.Q. approximately 60), Brushfield spots, 